\title{
A JUdiCIALIZAÇÃo DO CAIS: O LEGICENTRISMO NO ESTATUTO DO JUIZ
}

\author{
Marcelo Rubin de LIMA*
}

\begin{abstract}
RESUMO: Este artigo investiga o papel social dos juízes nos conflitos sobre a revitalização do Cais Mauá em Porto Alegre-RS. As expectativas quanto às ações do juiz neste conflito estruturaram práticas sociais mobilizadas pelos atores envolvidos no conflito. A análise do material empírico indicou que os movimentos sociais esperam que o juiz atue segundo o conceito operacional de "legicentrismo social", em que o juiz é percebido como aplicador da lei e protetor das pessoas desassistidas, aquelas que não conseguem acessar os espaços de tomadas de decisão da política administrativa do Estado. Esta noção coloca os magistrados diante de tensões sociais e expectativas que muitas vezes não podem ser correspondidas.
\end{abstract}

PALAVRAS CHAVE: Judicialização. Juiz. Legicentrismo. Cais Mauá.

\section{Introdução}

Este artigo investiga as reivindicações dos movimentos sociais em Porto Alegre-RS sobre a revitalização do Cais Mauá para revelar suas expectativas quanto às ações do juiz. A análise do material empírico indicou que os movimentos sociais esperam que o magistrado atue segundo o conceito operacional de "legicentrismo social", quando o juiz é percebido como aplicador da lei. Esta noção coloca os magistrados diante de tensões sociais e expectativas que muitas vezes não podem ser correspondidas. As concepções de justiça compartilhadas pelos atores em conflito estruturam discursos e práticas sociais que revelam o estatuto social do juiz.

\footnotetext{
Uniftec - Centro Universitário de Faculdades. Caxias do Sul - RS - Brasil. 95012-669 - rubin.lima@ ufrg.br. https://orcid.org/0000-0002-9775-7776
} 
Os dados apresentados nestes artigo fazem parte de um corpus de pesquisa que tem seu início em 2008. Trata-se de uma coleção de dados primários e secundários sobre os conflitos das associações de moradores da cidade de Porto Alegre-RS contra projetos imobiliário controversos ${ }^{1}$ (LIMA, 2017).

Bauer e Aarts (2002, p. 44) conceituam um corpus como "uma coleção finita de materiais, determinadas de antemão pelo analista". A coleção foi montada com dados de entrevistas, gravações de reuniões, observação participante, matérias de jornais, sites e blogs, além de documentos dos movimentos sociais e da Justiça. O corpus é trabalhado analiticamente após sua saturação. A coleção possui sincronia no tema, e se expande diacronicamente seguindo os novos eventos sobre o Cais Mauá. A narrativa desta categorização se concentra nos momentos em que os movimentos sociais, coletivos e associações de moradores organizavam sua mobilização; este recorte foi determinado pelo conceito de queixa. O conceito de legicentrismo foi usado analiticamente para revelar o estatuto social do juiz.

\section{A ideia de justiça como estruturante de práticas sociais}

Para Paul Ricoeur (1995) e Nanci Fraser (2014) as noções compartilhadas de justiça são um princípio ordenador do mundo social. Fraser (2014) pondera que a ideia de justiça é como uma virtude que serve de base para as demais virtudes. Por sua vez, Ricoeur (1995, p. 89) nota que "a ideia de justiça - quaisquer que sejam o sentido e o conteúdo - rege uma prática social". Tanto Ricoeur (1995) quanto Fraser (2014) comentam que ao acessar um tribunal os atores sociais não necessitam saber ou definir o que é a justiça, eles precisam apenas expressar uma injustiça que pode ocorrer ou ser percebida de diversas maneiras. Fraser (2014, p. 267) considera que "a justiça jamais se experimenta diretamente". Em contraste, a injustiça é experimentada diretamente. A injustiça existe positivamente, porque se constitui em uma experiência primeira. Ela concluiu que: "É apenas pela ponderação do que consideramos injusto que começamos a construir um sentido do que seria uma alternativa. Somente quando imaginamos o que seria preciso para superar a injustiça é que o nosso conceito de justiça deixa de ser vago e adquire conteúdo" (FRASER, 2014, p. 267).

Ricoeur (1995) também considera que a injustiça vem antes da justiça, ela é primeira. Com a queixa pública iniciamos a expressar o que é a injustiça e a justiça. Quando queremos estabelecer a justiça exclamamos: "Isso é injusto", "Que injustiça!". Por isso, perante o juiz nos comportamos como queixosos. Ricoeur (1995, p. 90) constata que, "a justiça é, mais amiúde, o que falta e a injustiça o que

Dados produzidos para o mestrado e doutorado do autor. 
reina, e os cidadãos têm uma visão mais clara do que falta às relações humanas do que da maneira correta de as organizar".

O conteúdo da justiça se materializa com base em uma queixa no tribunal. Esta é uma maneira de tentar organizar corretamente a ordem social, que, por ser complexa e plural, é de difícil compreensão para os atores envolvidos nos conflitos. Esta noção apresenta a justiça como a ação reflexiva entre agentes. A queixa perante o juiz expõe o que deve ser considerado justo por uma parte. No tribunal, os litigantes consideram que "recorrer ao juiz é recorrer à justiça, pois a natureza do juiz é ser uma espécie de justiça animada" (ARISTÓTELES, 1991, p. 105). O magistrado é percebido pela sociedade como a encarnação das noções abstratas de justiça. As queixas do cotidiano quando chegam ao tribunal constroem, por um lado, um princípio de justiça e por outro, um estatuto social do juiz. É pela queixa que os atores sociais determinam suas expectativas quanto ao justo e à ação do juiz.

\section{O legicentrismo como princípio de justiça e estatuto do juiz}

Nas sociedades democráticas o estatuto social do juiz suscita contradições devido às diferentes noções que existem sobre o fazer do magistrado. As representações idealizadas da figura do juiz são correntes. Segundo Allard (2009), o magistrado se localiza em uma verdadeira encruzilhada de expectativas sociais. Assim, para alguns, ele deve ser intransigente e duro em suas decisões; outros pensam que o juiz deve ter a sensibilidade do perdão. Ainda, enquanto alguns esperam que o magistrado julgue com cuidado e calma demonstrando estima pela lei, outros querem a velocidade e a precisão de uma máquina. A impossibilidade de cumprir todas estas expectativas demonstra que a sociedade espera muitas vezes o impossível do juiz. Allard (2009) considera que: "De fato, as expectativas a respeito do juiz, notadamente como assegurador dos direitos humanos, são às vezes desmedidas e correm o risco de refletir uma imagem impotente do magistrado. Esperávamos Deus e descobrimos humanos, demasiado humanos" (ALLARD, 2009, p. 12).

Koerner (2013), coloca que a figura do juiz e seu ativismo na sociedade se sustenta a partir da representação idealizada do governo constitucional, que lembra a noção romântica do contrato social. Esta visão descreve o percurso que levou os indivíduos livres a se submeterem voluntariamente a um conjunto de regras gestadas como se fossem em comum acordo. Esta é a ideia de que processos históricos resultaram em um ciclo político virtuoso que foi plasmado em constituições que, por sua vez, possuíam um germe civilizador apoiado sobre dois conceitos fundamentais: a representação popular e a proteção dos direitos individuais. Decorre desses fatores a noção de que todos os membros de uma sociedade são os autores da lei. 
Neste modelo, e ainda usando como referência trabalhos de Garapon (1999) e Koerner (2013), o juiz possui o papel social de protetor do pacto fundador, o ator que deve assegurar a realização dos princípios estabelecidos na constituição. Esta seria uma das bases do ativismo dos juízes. Ocorre que esta noção sobre um hipotético contrato social e seus conceitos abstratos correlacionados está longe de responder minimamente aos problemas do cotidiano de nossas democracias. Contudo, sustenta a noção de que o papel das instituições jurídicas é o de seguir as leis. Não haveria neste caso qualquer espaço para a interpretação ou mesmo criatividade por parte dos magistrados. Esta noção conceituo de legicentrismo social a partir da obra de Allard (2009).

Allard (2009) coloca a visão romântica da formação das constituições como um dos alicerces do legicentrismo e pilar da ordem jurídica moderna. A ideia de que, com auxílio da razão, se pode produzir um código legal completo, com muitos artigos, capaz de regrar a totalidade dos problemas sociais. Neste caso, as únicas normas jurídicas relevantes são as leis. A primazia da lei e sua anterioridade lógica é chamada de legicentrismo. Neste modelo, o juiz apenas segue a lei e, se acaso precisar fazer uma interpretação da lei, deve mantê-la estritamente no seu sentido original. Segundo esta posição, o juiz deve interpretar a lei com parcimônia, sem grandes arroubos criativos, pois a lei possui uma lógica própria que é anterior ao caso julgado e que responde perfeitamente aos problemas levantados no litígio. $\mathrm{O}$ conceito de centralidade da lei coloca a regra acima de qualquer opinião. A lei é vista como algo que não deixa dúvidas a serem resolvidas, pois ela é completa e, assim, refratária às divergências.

Na França revolucionária pós 1798, o legicentrismo se colocava como uma proteção dos ditames elevados da Revolução que deveriam ser preservados do corpo da magistratura ligada à nobreza, havia na época o receio de uma ditadura de juízes. O legicentrismo ao acentuar a criação da lei em uma assembleia popular, além de valorizar os ideais revolucionários, demonstrava também a fé na razão como melhor guia para resolver os conflitos humanos. De acordo com Allard (2009), a crença reta na supremacia e eficiência da lei também representa um dos principais motivos para a transformação das concepções sobre a figura e papel do juiz na sociedade. Allard (2009) argumenta que:

Verifica-se a seguir que o declínio da lei, hoje dessacralizada, põe em xeque o legicentrismo. Por diversas razões, em especial a complexidade do mundo, a lei perdeu sua legitimidade e sua eficácia: mostra-se inadaptada para oferecer respostas eficazes aos problemas que surgem neste mundo tecnológico, em plena evolução. Ou ela chega muito tarde ou é demasiado nacional, lá onde os problemas como a ecologia ou a Internet são universais. Em muitos casos, entre os quais o da incompletude de uma lei, espera-se que o juiz resolva este déficit (ALLARD, 2009, p. 10). 
No cotidiano, o legicentrismo social se manifesta nas queixas dos litigantes que são dirigidas ao juiz para que ele aplique a lei sem interpretação alguma, aspecto revelado pelo argumento: "tá na lei, cumpra-se a lei". Esta é a expectativa dos movimentos sociais que se opõem ao processo de revitalização do Cais Mauá em Porto Alegre-RS que será apresentado a seguir.

\section{A queixa dos movimentos sociais na questão do Cais Mauá}

O modelo de ocupação das margens do rio Guaíba pensado a partir de altos edifícios erguidos pela iniciativa privada enfrenta forte oposição em Porto AlegreRS. A verticalização da cidade gera diversas queixas dos moradores em diferentes bairros. No período entre 2001 e 2017 os movimentos e associações de moradores dos bairros centrais se envolveram em uma série de conflitos no entorno de questões sobre o planejamento urbano e o modelo de ocupação das margens do Guaíba. No centro desta disputa está a queixa dos movimentos sociais pelo cumprimento dos princípios do planejamento urbano previstos no Estatuto da Cidade.

Por outro lado, em Porto Alegre-RS há também uma intensa atividade a favor da ocupação das margens do Guaíba em organizações empresariais, veículos de comunicação e na internet. Estes são aqueles que vislumbram nos investimentos imobiliários e na indústria do turismo uma fonte certa e segura para o crescimento econômico. Assim os defensores do modelo de ocupação da orla centrado em grandes projetos imobiliários privados se referem aos movimentos que são contrários a este modelo como os "caranguejos do atraso". Pessoas que se opõem ao progresso e ao crescimento econômico da cidade a partir do seu cais.

Devido à disparidade no poder político e econômico entre os dois grupos, resta aos defensores da orla a queixa, a reclamação de uma falta grave feita pelos detentores dos poderes. As queixas das associações de moradores se direcionam ao juiz via Ações Civis Públicas (ACPs). Na questão do Cais Mauá está em jogo um terreno com números superlativos, 181 mil metros quadrados na margem do rio, na região central da cidade que tem mais de 1,4 milhão de pessoas (PORTO ALEGRE, 2020). Nos projetos pensados pelo poder público, nada de novo, todos contemplam o normal em termos de turismo e negócios, uma grande avenida com viadutos que levam a torres de escritórios, hotéis, shopping, restaurantes e centro de convenções, tudo cercado por um gigantesco estacionamento.

A confiança na eficácia das ACPs decorre dos conflitos ocorridos entre 2007 e 2009 em que estava em questão o projeto urbanístico do Pontal do Estaleiro, um antigo estaleiro localizado na ligação do centro com a zona sul. Em jogo, estavam as normas para construção de imóveis nas margens do rio. Após uma sucessão de ACPs, a solução jurídica para a questão foi a realização da primeira consulta popular 
do país para determinar aspectos do planejamento urbano. Com a participação de mais de 22 mil eleitores, a limitação na altura dos edifícios foi aprovada por $80,7 \%$ dos votantes. Naquele momento, a novidade das normas do Estatuto da Cidade possibilitou um incremento na confiança sobre o estatuto social do juiz centrado no conceito de legicentrismo, pois a queixa era para aplicar o Estatuto da Cidade, e o judiciário fez valer o que estava na lei. Este cenário inédito causou espanto e paralisia que deixou as organizações empresariais e a própria administração municipal sem saber o que fazer diante das queixas e da ativa mobilização que tomou conta dos bairros centrais exigindo o cumprimento do Estatuto.

O plebiscito de 2009 levou o prefeito da cidade a vetar a construção de torres comerciais com mais de 100 metros de altura próximo das extremidades do Cais Mauá, especificamente, no entorno da Usina do Gasômetro, que é tombada pelo patrimônio histórico e cultural, e da Rodoviária da cidade. Até este momento as queixas instrumentalizadas via ACP surtiram o efeito esperado pelos ativistas.

Segundo o planejamento urbano do município, a participação dos moradores do centro ocorreu institucionalmente nas reuniões da Região de Planejamento 1 (RP-1), que congregava os bairros centrais da cidade. A observação participante, realizada nas reuniões, constatou que os conselheiros da RP1 dialogaram com cidadãos, ONGs, coletivos, estudantes e os mais diversos movimentos sociais envolvidos nas questões urbanas. Em todas as reuniões, as potencialidades das ACPs foram destacadas. A articulação de denúncias ao Ministério Público (MP) e ACPs foi a ação mais indicada para solucionar as queixas contra a prefeitura e as empresas da construção civil. Nas reuniões os ativistas comentavam e destacavam os aspectos fundamentais das diversas queixas que eram trazidas e recomendavam: "Tem o MP, eles são obrigados aceitar este tipo de queixa".

Evidentemente a confiança extremada nos potenciais da lei e das normas muitas vezes não era correspondida pelos magistrados. Porém, os conselheiros e ativistas seguiam com a esperança de que as instituições jurídicas apenas aplicassem a lei sem questionamento. Por exemplo, em 2010, em uma reunião da RP1 uma conselheira fez a seguinte recomendação a um cidadão que apresentava uma queixa:

O senhor não desista, não existe ninguém que tenha mais poder que o senhor. Simplesmente o que o senhor tem que fazer é pegar as leis e ir ao MP e dizer: eu quero que cumpra a lei, não interessa se é coronel ou o que for! Só que o senhor tem que pegar e botar no papel, marcar com o MP e ir lá e dizer: eu quero que cumpra isso! Prefeito nenhum vai atender o senhor. Só em época de eleição. Escreva o que o senhor está dizendo aqui e vá ao MP.

Em 2010 o Governo do Estado cedeu a área do Cais Mauá para a iniciativa privada por um período de 25 anos. Na licitação houve apenas um concorrente. Esta 
foi a realização de um antigo sonho de muitos governos. O argumento que sustentou esta ambição foi a noção de que o cais deveria ser reintegrado ao centro da cidade, e seria função do poder público "devolver o rio para a cidade" e "reaproximar o porto-alegrense do rio". Acompanhava estes jargões o raciocínio de que o governo deveria repartir este projeto com a iniciativa privada como forma de não onerar os cofres públicos. E assim tivemos um projeto turístico internacional atrelado ao ideal de reintegrar o cidadão ao seu cais.

Foi neste momento que nasceu o coletivo Cais Mauá de Todos, que se opôs ao processo de licitação do cais. Sua origem era ligada aos movimentos espontâneos que se formaram logo após à concessão do cais. Entre estes movimentos, estava o coletivo Ocupa Cais Mauá. O “ocupa” buscou sua inspiração no movimento "Ocupa Estelita" de Recife-PE. Deve-se a isso a semelhança entre os nomes. Desde o início das articulações, a maior preocupação dos ativistas foi de encontrar uma maneira eficiente de impedir a demolição dos armazéns, ainda não tombados pelo patrimônio histórico e cultural, e, em decorrência disso, paralisar o processo licitatório. Assim, logo tomou forma a ideia de focar os esforços nas ações judiciais para que se fizesse cumprir a lei.

Para isso, o primeiro passo foi fazer o levantamento das principais questões judiciais do projeto de revitalização do cais. Este trabalho detectou indícios de irregularidade e ilegalidades em questões urbanísticas e no próprio edital de licitação. Entre as queixas do coletivo, estava o fato de que, em 2010, a Câmara Municipal havia aprovado o Projeto de Lei Complementar $n^{\circ} 638$, que estabeleceu as normas para a utilização da área do cais. Esta Lei conferiu índices construtivos especiais para o cais via parcerias público-privadas, art. 17. Nos documentos do coletivo, este ponto foi tratado como uma irregularidade da empresa que venceu a licitação, e assim a queixa endereçou-se a uma injustiça, pois no Estatuto consta:

- O art. 17 afirma que os regimes urbanísticos instituídos pela lei vigorarão até 32 de dezembro de 2012, e no seu $\S$ único cria a obrigação que nos primeiros 90 dias de 2013 o Executivo envie à Câmara Projeto contendo critérios de atualização da Lei, com a manutenção, modificação ou a revogação dos índices contidos. Isto não foi realizado, o que torna o regime urbanístico instituído sem efeito; - O mesmo art. 17 define as diretrizes estratégicas para o Cais Mauá. A primeira delas é o estudo de ligação aérea ou em nível, vegetada sobre a Avenida João Goulart, como até o presente momento o estudo não foi apresentado tal ato caracteriza descumprimento da obrigação legal; - A Lei concede alteração de uso e do direito de construir, que segundo o Estatuto da Cidade deveriam ser outorgas onerosas, mas são concedidas sem ônus, em contrariedade ao disposto na lei federal. Não bastasse isto a lei do município isenta da doação de áreas para sistema viário e equipamentos públicos e não prevê contrapartidas e medidas mitigadoras de 
impacto, previstas nestes casos pela Legislação Federal (Estatuto da Cidade); Na parceria pública privada é desejável que haja equilíbrio entre os benefícios concedidos pelo poder público e o ônus assumido pelo investidor privado em relação à concessão de 25 anos, sendo que a restauração dos armazéns é trocada pela possibilidade de edificação (1) um shopping center, (2) três torres comerciais de $100 \mathrm{~m}$ de altura e milhares de vagas de estacionamento, o que é, na relação custo benefício, extremamente desfavorável ao Poder Público (Documento Cais Mauá de Todos).

Somaram-se a esta queixa, outras, como os problemas licitatórios, entre eles a questão do princípio do procedimento formal, o princípio da publicidade de seus atos e o princípio da igualdade entre os licitantes. Desta forma, ficou claro que o melhor caminho a ser tomado pelos ativistas seria o de sustentar suas queixas contra a licitação nos tribunais.

Mas isso não foi consenso. Muitos ativistas do Ocupa Cais Mauá vislumbravam ações diretas como ocupações, passeatas e bloqueio de avenidas. O coletivo se dividiu. Desta dissidência surgiu o Cais Mauá de Todos. A queixa principal dos dissidentes era quanto às reuniões e ações do coletivo Ocupa Cais Mauá, consideradas como pouco efetivas e concentradas em objetivos muitos amplos, sem eficácia na luta pela preservação do Armazém A7. O objetivo específico do Cais Mauá de Todos era apenas parar a licitação. E para isso as melhores ações seriam as jurídicas.

Em entrevista dada ao blog da disciplina jornalismo ambiental do Centro Universitário Ritter dos Reis - UniRitter uma das líderes e fundadoras do coletivo Cais Mauá de Todos, comentou os motivos da separação do coletivo Ocupa Cais Mauá da seguinte forma: "Tínhamos o entendimento de que era preciso fazer a mobilização mais centrada em ações jurídicas, ações no âmbito institucional e também ter um discurso mais abrangente com o objetivo de conquistar as pessoas" (PEREIRA, 2015, n. p.).

Outra líder do Cais Mauá de Todos, em uma troca de e-mails, quando questionada sobre as expectativas com relação às ACPs respondeu: "O que esperamos do judiciário é algo bem cândido: justiça. Isso porque o contrato de arrendamento está com problemas e o consórcio já deixou de cumprir com obrigações consideradas fundamentais e que poderia dar por encerrado o negócio" (Corpus Cais Mauá).

Neste caso, a esperança de justiça se concentra na noção de que o juiz seguirá a lei, e a justiça é o equivalente à execução dos princípios do aparato de leis do Estado. A opção do Coletivo Cais Mauá de Todos de ter sua mobilização centrada em ações jurídicas se mostrou acertada e motivo de comemorações quando em 27 de outubro de 2015 o juiz federal Roberto Wanderley Nogueira decidiu que o terreno do Cais Estelita em Recife deveria retornar para a posse do poder público. 
Esta decisão é do Processo nº: 0001291-34.2013.4.05.8300, uma Ação Civil Pública do Ministério Público Federal contra o Instituto do Patrimônio Histórico e Artístico Nacional (IPHAN), a prefeitura e a empresa Novo Recife Empreendimentos LTDA., esta última é a responsável pela construção dos edifícios no cais Estelita. Na prática esta decisão anulou o leilão de venda da área.

Em Porto Alegre-RS, logo a notícia se espalhou pela internet, no jornal $J A ́$ a matéria de 29 de outubro de $2015^{2}$ trouxe a chamada: "Decisão judicial sobre o Cais Estelita anima ativistas de Porto Alegre". A matéria comentava que "a noite de sábado (28) foi de celebração diante do pórtico central do Cais Mauá". A reportagem destacou a troca de informações entre os dois movimentos e descreveu o comentário de uma ativista que pontuava: "Lá eles anularam um leilão, reverteram uma compra. Aqui é mais simples, basta rescindir o contrato".

O coletivo Cais Mauá de Todos fez dos conhecimentos jurídicos que adquiriu uma ferramenta para despertar o interesse midiático sobre suas queixas sobre a licitação do cais. Em coletiva de imprensa, realizada antes da audiência pública sobre o EIA-RIMA do projeto de revitalização, foram apresentadas mais queixas contra o contrato de concessão. Como resultado, no dia da audiência, o jornal Correio do Povo, em sua edição impressa do dia 18 de setembro de 2015, trouxe a seguinte manchete: "No STF, grupo quer evitar obra no Cais Mauá". No relatório entregue à imprensa o coletivo descreveu que:

O Coletivo Cais Mauá de Todos pretende levar ao IPHAN/Instituto do Patrimônio Histórico e Artístico Nacional o pedido de tombamento da Paisagem Histórica e Cultural do Cais Mauá, bem como a inclusão do Armazém A7 na proteção legal do conjunto tombado em nível municipal. Da mesma forma, está em andamento estudo para ingressar com Mandado de Segurança em nome da representação da Sociedade Civil junto ao TJ/RS e ao STF, por conta de inconstitucionalidades advindas da desobediência da Lei das Licitações (Lei Federal no 8.666/931) e da Lei da Transparência (Lei $n^{\circ} 12.741$ ). O presente relatório foi objeto de encaminhamento de providências às denúncias em nome do Coletivo Cais Mauá, devidamente registradas em abaixo-assinado com mais de 6.500 assinaturas, para legitimidade do espírito cívico desta ação, junto aos órgãos competentes em todas as esferas públicas de âmbito Municipal, Estadual e Federal (Documento CAIS MAUÁ DE TODOS, relatório setembro 2015).

Em abril de 2018, a suspeita do coletivo Cais Mauá de Todos revelou-se concreta quando uma operação da Polícia Federal encontrou evidências de fraude no fundo de investimentos que financiava as obras de revitalização do Cais Mauá.

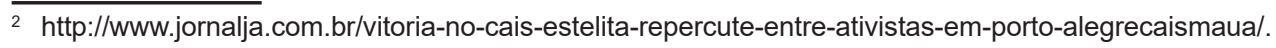


Entretanto, as obras não foram paralisadas devido às ACPs, mas sim devido a uma investigação paralela. Um mês antes, em março de 2018, a prefeitura e o governo do Estado liberaram as autorizações para o início das obras o que acarretaria na demolição dos armazéns não tombados pelo patrimônio histórico e cultural. As expectativas quanto à eficácia das ACPs não se concretizaram até o momento. A esperança depositada no juiz como articulador do legicentrismo social e protetor dos desassistidos nas decisões sobre o planejamento urbano de Porto Alegre não aconteceram. Até este momento, a questão da revitalização do Cais Mauá é incerta.

\section{Considerações finais}

A centralidade das ACPs nos conflitos urbanísticos e ambientais de Porto Alegre-RS é taken for granted. Os ativistas e apoiadores da defesa do Cais Mauá seguirão usando as ACP como um destacado repertório de ação. Entretanto, as queixas dos defensores do Cais Mauá não foram atendidas. A expectativa quanto à atuação do juiz não se concretizou. Em Porto Alegre-RS o estatuto social do juiz está em ebulição. A queixa para que se cumpra o Estatuto da Cidade suscita a noção de que o juiz deve aplicar a lei. Isso exclui a criatividade e interpretação do magistrado e pressupõem que a lei é completa e sua aplicação autoevidente. A posição legicentrista espera que o juiz atue semelhante a uma máquina de julgar. Ocorre que a lei está dessacralizada. Embora o Estatuto da Cidade tenha objetivos virtuosos, sua execução gera dúvidas e não é automática. A incompletude da lei gera espaços para o juiz atuar de diferentes formas. Esperar que o juiz apenas cumpra a lei é reduzir sua capacidade de ação. O magistrado pode articular e conciliar. Além disso, a queixa centrada na questão legal obscurece conflitos de fundo, como os modelos alternativos de planejamento urbano.

\section{THE JUDICIALIZATION OF THE HARBOR: THE LEGICENTRISM IN THE STATUTE OF THE JUDGE}

ABSTRACT: This article investigates the social role of the judges in the judicialization of the revitalization of Mauá harbor in Porto Alegre, RS, Brazil. Expectations as to the actions of the judge in this conflict structured social practices mobilized by the people involved in the conflict. The analysis of the empirical material indicated that the social movements expect the judge to act according to the operational concept of "social legicentrism", in which the judge is perceived as an enforcer of the law and protector of the unassisted people, those who cannot access 
the decision-making spaces of the State administrative policy. This notion places the magistrates in face of social tensions and expectations which are often not met.

KEYWORDS: Judicialization. Judge. Legicentrism. Mauá Harbor.

\section{LA JUDICIALIZACIÓN DEL PUERTO: EL LEGICENTRISMO EN EL ESTATUTO DEL JUEZ}

RESUMEN: Este artículo investiga el papel social de los jueces en la judicialización de la revitalización del puerto de Mauá en Porto Alegre. Las expectativas sobre las acciones del juez en este conflicto estructuraron las prácticas sociales movilizadas por los actores involucrados en el conflicto. El análisis del material empírico indicó que los movimientos sociales esperan que el juez actúe de acuerdo con el concepto operativo del "legicentrismo social", en el que el juez es percibido como un ejecutor de la ley y protector de las personas sin asistencia, aquellos que no pueden acceder a los espacios de toma de decisiones de la política administrativa del Estado. Esta noción coloca a los magistrados ante tensiones sociales y expectativas que a menudo no se cumplen.

PALABRAS CLAVE: Judicialización. Juez. Legicentrismo. Cais Mauá.

\section{REFERÊNCIAS}

BAUER, Martin; AASTS, Bas. A construção do corpus: um princípio para a coleta de dados qualitativos. In: BAUER, Martin W.; GASKELL, George (ed.). Pesquisa Qualitativa com texto, imagem e som: um manual prático. Petrópolis: Vozes, 2002.

ALLARD, Julie. Le juge en France, un statut en pleine évolution? Paris: Dalloz, 2009.

ARISTÓTELES. Os pensadores, v2. São Paulo. Nova Cultural, 1991.

CORREIO DO POVO. "No STF, grupo quer evitar obra no Cais Mauá". Publicado em 18 de setembro de 2015. Disponível em: http://www.jornalja.com.br/vitoria-no-cais-estelitarepercute-entre-ativistas-em-porto-alegrecaismaua/. Acesso em: 13 mai. 2020.

FRASER, Nancy. Sobre justiça: lições de Platão, Rawls e Ishiguro. Rev. Bras. Ciênc. Polít, Brasília, n. 15, p. 265-277, 2014.

GARAPON, Antoine. O juiz e a democracia: o guardião das promessas. Rio de Janeiro: Revan, 1999. 
KOERNER, Andrei. Ativismo judicial? Jurisprudência constitucional e política no STF pós88. Novos Estudos - CEBRAP, São Paulo, n. 96, p. 69-85, 2013.

LIMA, Marcelo Rubin. A justiça e a cidade: o juiz nas lutas pela ocupação do espaço urbano de Porto Alegre. Tese de doutorado, Programa de Pós-Graduação em Sociologia, Universidade Federal do Rio Grande do Sul. Porto Alegre, 2017.

PEREIRA, Juliana. KATIA SUMAN: "O espaço público precisa permanecer público". Jornalismo Ambiental. UniRitter, 15 de julho de 2015. Disponível em: http:// jornalismoambiental.uniritter.edu.br/?p=776. Acesso em: 13 mai. 2020.

PORTO ALEGRE. Prefeitura. Dados Demográficos IBGE 2010. Disponível em: http:// www2.portoalegre.rs.gov.br/sms/default.php?p_secao=918. Acesso em: 13 mai. 2020.

RICOEUR, Paul. Em torno ao político. São Paulo: Edições Loyola, 1995.

Recebido em 17/08/2018.

Aprovado em 04/02/2020. 